Available online at GSC Online Press Directory

GSC Advanced Research and Reviews e-ISSN: 2582-4597, CODEN (USA): GARRC2

Journal homepage: https://www.gsconlinepress.com/journals/gscarr

(RESEARCH ARTICLE)

\title{
Ferritin and genu joints ultrasound in major-beta thalassemia
}

\author{
Widiastuti Soewondo ${ }^{1}$, Nur Arif Wibowo ${ }^{1}$, Muchtar Hanafi $1,{ }^{*}$, Amelia Tjandra Irawan ${ }^{1}$, Sulistyani \\ Kusumaningrum ${ }^{1}$, Muhammad Riza ${ }^{2}$, Ari Probandari ${ }^{3}$ and Luths Maharina ${ }^{1}$ \\ ${ }^{1}$ Radiology Department of Dr. Moewardi Public Hospital, Faculty of Medicine, Universitas Sebelas Maret, Surakarta \\ Indonesia. \\ ${ }^{2}$ Pediatric Department of Dr.Moewardi Public Hospital, Faculty of Medicine, Universitas Sebelas Maret, Surakarta \\ Indonesia. \\ ${ }^{3}$ Public Health Department, Faculty of Medicine, Universitas Sebelas Maret, Surakarta Indonesia.
}

Publication history: Received on 16 December 2020; revised on 23 December 2020; accepted on 25 December 2020

Article DOI: https://doi.org/10.30574/gscarr.2020.5.3.0132

\begin{abstract}
Objective: This study aims to determine whether there is a relationship between ferritin levels and the ultrasound of genu joints in Major-beta Thalassemia patients who undergo repeated transfusions.

Methods: 43 major-beta thalassemia patients who met the inclusion criteria had their genu joint examined by ultrasonography in the Radiology Department of Dr. Moewardi Hospital Surakarta. We analyzed several variables related to synovial thickening, synovial vascularization and joint effusion in these patients.

Results: From 43 samples, the median value of ferritin was 2976.8 (702.2-8897.7) ng/mL and the median of average transfusion was 15 (5-67) times. Analysis with Mann Whitney's non-parametric hypothesis test showed a statistically significant relation between ferritin levels and the presence or absence of ultrasonographic genu joint manifestations in general $(p=0.006)$ and hypoechoic synovial joint thickening $(p=0.020)$

Conclusion: Major-beta thalassemia patients with ferritin levels> $2976.8 \mathrm{ng} / \mathrm{mL}$ had a 1.73 times higher risk for thickening of the synovial joints and 1.50 times higher for having genu joint manifestations. The frequency of transfusion showed a statistically significant relationship with the thickening of the synovial joint. Repeated transfusions more than 15 times increased the prevalence of the synovial joints thickening by 1.57 times.
\end{abstract}

Keywords: Ferritin; Genu; Beta-thalassemia; Ultrasound

\section{Introduction}

Thalassemia is a serious public health problem in the world, especially in Mediterranean countries, Malaysia, Thailand, and Indonesia. ${ }^{1}$ More than $3 \%$ of the world's population has the thalassemia gene where the highest incidence rate that up to $40 \%$ of cases occurs in Asia. ${ }^{2}$ In Indonesia, thalassemia is the most common disease among hemolytic anemia groups with intra-corpuscular causes. Major-beta thalassemia as a genetic disease that affects a lifetime will bring many problems for the patient. Starting from blood disorders due to anemia, the process of hemolysis, to abnormalities of various organs both caused by the disease itself or the side effects of the treatment. Hemoglobin (Hb) levels $<10$ gr\% occur in $99.1 \%$ of major-beta thalassemia patients. To this day, blood transfusion is still the main treatment for managing anemia in major-beta thalassemia. 3,4

\footnotetext{
* Corresponding author: Muchtar Hanafi

${ }^{1}$ Radiology Department of Dr. Moewardi Public Hospital, Faculty of Medicine, Universitas Sebelas Maret, Surakarta Indonesia.

Copyright (C) 2020 Author(s) retain the copyright of this article. This article is published under the terms of the Creative Commons Attribution Liscense 4.0.
} 
Iron overload that occurs in thalassemia patients requires a lifetime chelation therapy. Chelation agent is suspected as one of the factors that cause joint disorders that are common in thalassemia patients. 5,6 One of a non-invasive way to find out joint disorder is the detection of the joint with ultrasonography. In this study, we wanted to find out the correlation between ferritin levels with USG of joints in major-beta thalassemia patients that undergo repeated transfusions in Dr. Moewardi General Hospital.

\section{Methods}

We used observational analytic design with a cross-sectional approach using medical records at Dr. Moewardi Hospital. We included patients with a diagnosis of thalassemia proven by $\mathrm{Hb}$ Electrophoresis examination and underwent routine transfusion in the pediatric department of Dr. Moewardi Hospital from February to August 2019, there were 43 patients who met the inclusion criteria and had a complete medical record.

The inclusion criteria were 1) patient diagnosed with beta major thalassemia based on clinical symptoms and $\mathrm{Hb}$ electrophoresis; 2) aged over 2 years; 3) had a complete data record of ferritin level; 4) parents/guardians signed the consent form following the study. Exclusion criteria of this study were 1) patients who had transfusion for the first time; 2) patients with a history of trauma.

Each patient has an ultrasonography examination that contained: 1) synovial thickening; 2) synovial vascularization; 3 ) genu effusion, which was done by 2 radiologists with more than 3 years experiences. The last ferritin level was taken from the report card. Gender, age, duration of diagnosis and frequency of transfusion written on the report card were collected and statistically analyzed using SPSS version 25.0.

\section{Results}

Table 1 Reliability tests using the Kappa-Cohen test

\begin{tabular}{|l|l|l|l|l|}
\hline & \multicolumn{2}{|l|}{ Radiologist 1 } & \multirow{2}{*}{ p value } & \multirow{2}{*}{ K value } \\
\hline & Synovial thickening & No synovial thickening & & \\
\hline $\begin{array}{l}\text { Radiologist 2 } \\
\begin{array}{l}\text { Synovial thickening } \\
\text { No synovial thickening }\end{array}\end{array}$ & 1 & 0 & 0.035 & 0.615 \\
& 1 & 8 & & \\
\hline
\end{tabular}

The kappa-cohen test showed a p value of 0.035 and a K value of 0.615 which stated that the ultrasound instrument had fulfilled the reliability test to be used in this study.

Table 2 Sociodemographic characteristics of the samples

\begin{tabular}{|l|l|l|}
\hline Variable & Number & Percentage (\%) \\
\hline Sex & & \\
Male & 18 & 41.9 \\
Female & 25 & 58.1 \\
\hline Age (year (mean (SD)) & $10.58(5.75)$ & \\
\hline
\end{tabular}

Table 2 presents the sociodemographic characteristics of the sample consisting of gender and age. Our samples contained 18 male (41.9\%) and 25 females (58.1\%). The mean age was $10.58+5.75$ years. The age variable was presented in the mean + SD form because it had a numerical scale and a normal data distribution. 
Table 3 Clinical characteristics of the samples

\begin{tabular}{|l|l|l|}
\hline Variable & Number & Percentage (\%) \\
\hline Ferritin Level $(\mathrm{ng} / \mathrm{mL})$ & $2976.8(702.3-8897.7)$ \\
\hline Iron Serum $(\mu \mathrm{g} / \mathrm{dl})$ & $155(50-240)$ \\
\hline TIBC $(\mathrm{g} / \mathrm{dl})$ & $224.4 \pm 28.8$ \\
\hline Hemoglobin (g/dl) & $11.9 \pm 1.8$ \\
\hline Transfusion Frequency (times) & $15(5-67)$ & \\
\hline Diagnosis Duration (years) & $5(1-15)$ & 23.3 \\
\hline Joint Manifestation & \multicolumn{2}{|l|}{} \\
Yes & 10 & 76.7 \\
No & 33 & \\
\hline Synovial Joint Thickening & 15 & 34.9 \\
No & 16 & 37.2 \\
Mild & 12 & 27.9 \\
Moderate & & 60.5 \\
\hline Synovium Vascularisation & 26 & 39.5 \\
No & 17 & 90.7 \\
Spot Signal & & 9.3 \\
\hline Knee Joint Efusion & 39 & \\
No & 4 & \\
Yes & & \\
\hline
\end{tabular}

Table 4 Hypothesis test relationship between ferritin levels and joint ultrasound results using mann whitney nonparametric test

\begin{tabular}{|l|l|l|}
\hline Variable & Number & p value \\
\hline $\begin{array}{l}\text { Joint Manifestation } \\
\text { No }\end{array}$ & 10 & 0.006 \\
Yes & 33 & \\
\hline $\begin{array}{l}\text { Synovial Joint Thickening } \\
\text { No }\end{array}$ & 15 & 0.020 \\
Yes & 28 & \\
\hline Synovial Joint Thickening & & 0.963 \\
Mild & 16 & \\
Moderate & 12 & \\
\hline Synovium Vaskularisation & & 0.495 \\
No & 26 & \\
Spot Signal & 17 & \\
\hline Knee Joint Efusion & & 0.167 \\
No & 39 & \\
Yes & 4 & \\
\hline
\end{tabular}


The results of hypothesis testing using Mann Whitney non-parametric test found a statistically significant relationship between ferritin levels and the presence or absence of overall joint manifestations based on the results of ultrasonographic examination $(\mathrm{p}=0.006)$ and thickening of the hypoechoic synovial joints $(\mathrm{p}=0.020)$. Ferritin levels did not have a statistically significant relationship with intensity of synovial joint thickening $(p=0.963)$, increased synovial vascularity $(p=0.495)$, and the presence or absence of effusion in the knee joint $(p=0.167)$.

Table 5 Hypothesis test relationship between variable transfusion frequency and joint ultrasound examination results using mann whitney non-parametric test

\begin{tabular}{|l|l|l|}
\hline Variabel & Number & p value \\
\hline Joint Manifestation & & 0.077 \\
No & 10 & \\
Yes & 33 & \\
\hline Synovial Joint Thickening & 15 & 0.026 \\
No & 28 & \\
Yes & 16 & 0.423 \\
\hline Synovial Joint Thickening & 12 & \\
Mild & & 0.566 \\
Moderate & 26 & \\
\hline Synovium Vaskularisation & 17 & \\
No & 39 & \\
Spot Signal & 4 & \\
\hline Knee Joint Efusion & \\
No & & \\
Yes & & \\
\hline
\end{tabular}

The results of hypothesis testing using Mann Whitney non-parametric test found a statistically significant relationship between variable frequency of transfusion and the presence or absence of synovial joint thickening $(p=0.026)$. The frequency of transfusion frequency did not have a statistically significant relationship with overall joint manifestations based on ultrasound examination results $(p=0.077)$, intensity of synovial joint thickening $(p=0.423)$, increased synovial vascularization $(p=0.566)$, and the presence or absence of effusion in the joint knee $(p=0.805)$.

Table 6 Transfusion frequency hypothesis testing with synovial joint thickening

\begin{tabular}{|c|l|l|l|l|}
\hline & \multicolumn{2}{|l|}{ Synovial Joint Thickening } & \multirow{2}{*}{ p value } & \multirow{2}{*}{ Prevalence-Ratio (95\%CI) } \\
\hline & Yes & No & & \\
\hline $\begin{array}{c}\text { Number of } \\
\text { Transfusion }\end{array}$ & & & 0.052 & $1.57(0.96-2.55)$ \\
$>15$ times & 18 & 5 & & \\
$<15$ times & 10 & 10 & & \\
\hline
\end{tabular}

\section{Discussion}

The main therapy for thalassemia patients is blood transfusion, especially red blood cells. Blood transfusion therapy is carried out routinely and periodically with various frequencies depending on clinician decisions. The target of blood transfusion therapy is a hemoglobin level of 9.5-10.5 g/dl.4,5,6 Iron is one of the main components of red blood cells, so that transfusion of red blood cells can increase the amount of iron in the patient's body. The greater the number of red blood cells transfusion correlates with a greater amount of iron in the body. The effectiveness of hematopoiesis in major-beta thalassemia patients also contributes to increasing levels of iron in the body. Red blood cell transfusion 
therapy and ineffectiveness of hematopoiesis contribute to the buildup of iron in many organs which can lead to organ damage. ${ }^{7}$

Ferritin, a protein that acts as an iron carrier in the bloodstream, is one of the laboratory markers that can represent the total amount of iron in the body. ${ }^{8}$ Blood ferritin levels have a positive correlation with the amount of iron in the body in most clinical conditions. Blood ferritin levels also have a correlation with the volume of blood or frequency of transfusion, which indirectly has a positive correlation with the degree of major-beta thalassemia. ${ }^{9}$

The results of the median levels of ferritin in the blood obtained by this study were $2976.8 \mathrm{ng} / \mathrm{mL}$ with a minimum value of $702.2 \mathrm{ng} / \mathrm{mL}$ and a maximum of $8897.7 \mathrm{ng} / \mathrm{mL}$. Our study showed high blood ferritin levels, which were in accordance with the profile of beta major thalassemia patients who had undergone repeated blood transfusions. The study of Mishra A, et al. also showed an average high blood ferritin level in major-beta thalassemia patients that was $2672.52 \mathrm{ng} / \mathrm{mL}$, even the research of Riaz H, et al. showed an average higher blood ferritin level of $4236.5 \mathrm{ng} / \mathrm{mL}$. 7,10

The blood ferritin levels of the subjects of this study disputed a considerable difference with the average blood ferritin levels of children aged 6-15 years who were in the range of 7-140 ng/mL, even disputing the significant difference with the average ferritin levels of adults, namely $20-250 \mathrm{ng} / \mathrm{mL} \cdot{ }^{11}$ High levels of blood ferritin in the subject indirectly indicate high levels of total iron in the subject's body. High levels of total iron in the subject's body correlate with the severity of major-beta Thalassemia which requires a high amount and/or frequency of blood transfusions from a young age.

The mean of the subjects' ages in this study was 10.58 years with an even distribution of sex (male: female $=41.9 \%$ : $58.1 \%$ ). These results are consistent with the study of Kadhim, et al, which states that $41.70 \%$ of thalassemia patients are within the age range of 6-15 years and gender distribution in thalassemia patients is evenly distributed.5 Aydinok, et al's study also states that the majority of thalassemia patients are in the age range of 10-20 years with an even distribution of gender. ${ }^{6}$

The median transfusion frequency of the subjects in this study was 15 times. Aydinok, et al's study, states that the frequency of thalassemia patients undergoing repeated transfusions is more than 8 times a year. ${ }^{12}$ The median length of patients has been diagnosed with major-beta thalassemia until the study time is 5 years. The average length of time a patient has been diagnosed with a diagnosis of major-beta thalassemia is a relatively different thing for each study conducted, so there is no comparative study that can be taken into consideration.

Joint disorders are one of the clinical manifestations that are often found in major-beta thalassemia. Rawi, et al. study showed that joint manifestations occurred in $54.3 \%$ of beta major Thalassemia patients, whereas the multicenter study by Nouredine, et al. showed an incidence range of $16-30 \%$ for joint manifestations in major-beta Thalassemia patients. ${ }^{13,14}$ Our results showed a prevalence of joint manifestations of $76.7 \%$. Our study subjects had a higher prevalence rate for joint manifestations than similar studies. Clinical manifestations of joints in major-beta Thalassemia patients can occur in various types of diseases, including rheumatoid arthritis, osteoarthritis, arthropathy related to deferiprone therapy, arthritis or arthropathy related to excess iron in the body, crystal arthritis, septic arthritis, and joint effusion. ${ }^{15}$

The pathophysiology of joint abnormalities in patients with major thalassemia is still unclear at this time. B-globin gene locus that has abnormalities in major-beta thalassemia is believed to be related to genes that triggers the development of the systemic autoimmune disease, where the joint is one of the main targets, in patients with major-beta thalassemia. Excessive iron in the body is also one factor that is thought to play a role in joint manifestations experienced by majorbeta thalassemia patients, but the underlying pathophysiology is unclear. One hypothesis is that excessive iron can cause tissue damage by free radical formation. Research conducted using animal models shows that excessive iron can worsen degeneration of joint discs. ${ }^{16}$

Increasing age will cause the condition of major thalassemia to be more severe, so the number and frequency of blood transfusions will also increase. The higher age is also associated with longer subjects diagnosed with major-beta thalassemia. An increase in the amount of blood transfusion is positively correlated with an increase in iron deposits in the body thereby increasing the likelihood of joint problems. The similarity of pathophysiology is the basis of the hypothesis of the relationship between age, frequency of transfusion, and duration of diagnosis with joint manifestations in patients with major-beta thalassemia.

Joint ultrasonography is one modality that can be used to examine joint abnormalities in major-beta thalassemia patients. Our results showed $66.1 \%$ of the subjects had synovial joint thickening, $30.5 \%$ of the subjects had increased 
synovium vascularization and $9.3 \%$ of the subjects had knee joint effusion. Atta, et al. study using ultrasonography in the knee joint showed that major-beta thalassemia patients had an incidence of synovitis (23.8\%), joint effusion (14.3\%), metaphysis dysplasia (85.7\%), and increased power doppler signal (19\%).35 Based on the results of this study, supported by other studies, we can say that joint problems are common among major-beta thalassemia patients.

Excessive iron in the body is one of the factors believed to contribute to joint manifestations experienced by major-beta thalassemia patients, although the underlying pathophysiology is unclear. ${ }^{17}$ The high number and frequency of blood transfusion in major-beta thalassemia patients also contribute to higher levels of iron in the body, which can be represented by increased blood ferritin levels. ${ }^{7}$ If excessive iron is a cause and is involved in the pathophysiology of joint manifestations in major-beta thalassemia patients, the higher iron levels in the body will lead to a higher likelihood of joint manifestations appear. Based on the above findings we have a hypothesis that ferritin levels in the blood have a statistically significant relationship with joint manifestations.

Our results showed a statistically significant relationship between blood ferritin levels and overall joint manifestations and the presence of synovial joint thickening but did not show a statistically significant association with increased synovium vascularity and knee joint effusion. The use of traditional ferritin cut-off levels of $1000 \mathrm{ng} / \mathrm{mL} \mathrm{did} \mathrm{not} \mathrm{show}$ significant results on the five variables, but the use of the median $(2976.8 \mathrm{ng} / \mathrm{mL})$ as a cut-off showed significant results on the overall joint manifestation variables and thickening of the synovial joints. Major-beta thalassemia patients with ferritin levels $>2976.8 \mathrm{ng} / \mathrm{mL}$ had a higher risk of 1.73 times of synovial joint thickening and 1.50 times higher of overall joint manifestations based on ultrasonographic results. Based on the results of this study, it can be said that joint manifestations are more at risk in patients with major-beta thalassemia with blood ferritin levels greater than 2976.8 $\mathrm{ng} / \mathrm{mL}$.

To our knowledge, there are no studies in Indonesia, even in the world, that examines the relationship between joint manifestations based on ultrasound examination in major-beta thalassemia patients and blood ferritin levels. Therefore, this study can be regarded as the first study examining the relationship between the two variables.

Our results did not show a statistically significant relationship among age, sex, and frequency of transfusion with joint abnormalities variables based on ultrasound examination. The frequency of transfusions shows a statistically significant association with the thickening of the synovial joint. The frequency of transfusion more than 15 times increased the prevalence of synovial joint thickening by 1.57 times.

Based on multivariate analysis, there were no significant results on the variables studied. The order of influence from highest to lowest is determined by the value of $\mathrm{p}$. The order of influence on overall joint manifestations includes the length of diagnosis, frequency of transfusion, sex, age, and ferritin levels. The order of influence on synovial joint thickening includes ferritin levels, duration of diagnosis, sex, frequency of transfusion, and age. The order of influence on the increase in joint vascularization includes the length of diagnosis, frequency of transfusion, age, ferritin levels, and sex. The order of influences on knee joint effusion included ferritin levels, sex, age, length of diagnosis, and frequency of transfusion.

Joint disorders in major-beta thalassemia patients can be broadly divided into two categories, namely arthritis and arthropathy. ${ }^{15}$ Excessive amounts of iron in the body can manifest as arthritis or arthropathy. ${ }^{17}$ Based on our results, a statistically significant association was found in synovial joint thickening. Synovial joint thickening is a sign of joint inflammation or synovitis, which has been proven in rheumatoid arthritis and osteoarthritis. ${ }^{18}$ Findings of synovitis and synovial joint thickening on ultrasonography is a sign of inflammation in the joints. No statistical significant association was found in the variable increase in synovium vascularization which is one sign of joint inflammation. This finding did not eliminate evidence of joints inflammation because not all joint inflammation is accompanied by a significant increase in synovium vascularization. ${ }^{19}$

Based on the above findings, it can be said that joint abnormalities that were found to have a statistically significant relationship with ferritin levels in our study were arthritis or inflammation of the joints. Joint manifestations in the form of arthropathy are outside the scope of the predicted value of ferritin levels obtained in our study.

Research by Al-Rawi, et al. states that joint abnormalities in patients with major-beta thalassemia are not related to age and sex, but have a statistically significant relationship with the frequency of transfusion. ${ }^{13}$ Haine et al. states that joint abnormalities in patients with major-beta thalassemia are not related to age. ${ }^{20}$ These results are consistent with this study where the frequency of transfusion has a statistically significant relationship with joint abnormalities in patients with major-beta thalassemia. 
The use of only one modality in the joint examination, namely ultrasonography, to ascertain joint manifestations or abnormalities is one of the limitations of our study. Ultrasonography is a radiology instrument that is operator dependent and prone to bias. The reliability test is still not $100 \%$ able to eliminate this bias. The power doppler instrument used in this study is also prone to bias results due to engine conditions and the acoustic condition of the examination room. ${ }^{19}$ The results are not significant or even significant in a study even though it cannot be separated from the inspection bias.

The use of only one modality is a limitation of our study which is thought to have contributed to a statistically insignificant result in the variables of synovium vascularization and knee joint effusion. The use of more than one modality, for example, CT-Scan or MRI, to perform joint examination is a suggestion that we can propose to overcome the limitations.

The exclusion and analysis of variables using iron chelation therapy, especially deferiprone, is another limitation of this study which could contribute to the insignificant results of the study for knee joint effusion variables. Joint effusion can appear in joint inflammation, but specifically, in patients with major-beta thalassemia, the appearance of joint effusion has more correlation with the side effects of iron chelation therapy, namely deferiprone. Joint effusion due to iron chelation is known as deferiprone-related arthropathy. ${ }^{15}$

The unanalyzed factor in the administration of iron chelation therapy, coupled with joint manifestations that lead to arthritis in this study, is a contributor to the insignificant results of research on joint effusion variables. Inclusion of variable administration of iron chelation therapy supplemented by type, frequency, and dose, is a solution we can offer from the limitation of this study.

The limited number of samples due to the limited duration of the study and the number of patients who met the inclusion criteria also contributed to the existence of significant results in this study. The greater the number of study samples, the greater the reliability of a study, which can contribute to a more significant $p$-value. ${ }^{21}$ An increase in the number of samples accompanied by extended study duration and collaboration with other research center hospitals is the solution we propose for this limitation.

Hypothesis testing showed the significance of blood ferritin levels with overall joint manifestations and synovial joint thickening and frequency of transfusion with a synovial joint thickening. Blood ferritin levels $>2976.8 \mathrm{ng} / \mathrm{dl}$ could be used as predictors of overall joint manifestations and thickening of synovial joints in patients with major-beta thalassemia. The frequency of transfusion> 15 times could be used as a predictor of synovial joint thickening in patients with major-beta thalassemia.

Although the results of the study stated that the increase of the variables in synovium and knee joint effusion did not have a statistically significant relationship with blood ferritin levels in major-beta thalassemia patients, this was not in accordance with the logic of pathophysiology and characteristics of joint abnormalities in major-beta thalassemia patients. The author believe that if all the limitations of the research described above can be overcome, it is very possible to find a statistically meaningful relationship between the two variables. Further research with more diverse methods, longer duration, and a larger subject need to be done to prove the relationship between the two variables.

\section{Conclusion}

Based on the results of this study, we can conclude that the median value of blood ferritin levels in this study was 2986.7 $\mathrm{ng} / \mathrm{mL}$. The prevalence of joint manifestations in this study was 76.7\%, synovial joint thickening $65.1 \%$, increased synovial vascularization $39.5 \%$ and knee joint effusion $9.3 \%$.

The median value of diagnosis time and frequency of transfusion in this study was 5 years and 15 times. This study is the first study in the world to examine the relationship between joint manifestations based on ultrasound examination results and blood ferritin levels, age, sex, frequency of transfusion, and duration of diagnosis in patients with major-beta thalassemia.

There were significantly different results between joint manifestations and synovial joint thickening with blood ferritin levels. There was a significantly different result between the thickening of the synovial joint and the frequency of transfusion. 
No significant results were obtained between joint abnormalities with age and gender. Research limitations in the examination method, duration, and subject of research are factors that contribute to the results that are not significantly different.

\section{Compliance with ethical standards}

\section{Acknowledgments}

We would like to thank to the patients who had been the subject of this study.

\section{Disclosure of conflict of interest}

There is no conflict of interests. The authors report no conflicts of interest in this work. By this statement, all authors who consist of Widiastuti Soewondo, Nur Arif Wibowo, Muchtar Hanafi, Amelia Tjandra Irawan, Sulistyani Kusumaningrum, Muhammad Riza, Ari Probandari have no conflict of interest regarding this manuscript publication.

\section{Statement of informed consent}

Informed consent was obtained from the patients whose data mentioned in the study.

\section{References}

[1] Wahidiyat I. Thalassemia dan Permasalahannya di Indonesia. Naskah Lengkap Konika XI. IDAI: Jakarta. 2009.

[2] Abetz L, Baladi JF, Jones P, Rofail D. The impact of iron overload and its treatment on quality of life: result from a literature review. Health and Quality of life outcomes. 2006; 4: 73.

[3] Malik S, Syed S, Ahmed N. Complications in transfusion-dependent patients of ß-thalassemia major. 2009.

[4] Karimi M, et al. Prevalence of hepatosplenomegaly in beta thalassemia minor subjects in Iran. European Journal of Radiology. 2009; 69: 120-2.

[5] Thalassemia International Federation: Guidelines for the clinical management of thalassemia 2nd edition. 2008.

[6] Borgna-Pignatti C, Galanello R. Thalassemias and related disorders: quantitative disorders of hemoglobin synthesis. In Wintrobe's Clinical Hematology Volume 42. 11th edition. Lippincott Williams \& Wilkins. Philadelphia. 2004; 1319-1365.

[7] Mishra AK, Tiwari A. Iron overload in beta thalassaemia major intermedia patients. Maedica. 2016; 8(4): 328-32.

[8] Wang W, Knovich MA, Coffman LG, Torti FM, Torti SV. Serum ferritin: past, present and future. Biochimica et Biophysica Acta. 2010; 1800(8): 760-9.

[9] Pootrakul P, Vongsmassa V. Serrum Ferritin Level in Thalassemias and The Effect of Splenectomy. Acta Haematologica. 1984; 66(4): 244-50.

[10] Riaz H, et al. Serum ferritin levels, socio-demographic factors and desferrioxamine therapy in multi-transfused thalassemia major patients at a government tertiary care hospital of Karachi, Pakistan. BMC Research Notes. $2011 ; 287$.

[11] University of Rochester Medical Center. Ferritin (Blood).

[12] Minardi J, Denne N, Miller M, Larrabee H, Lander O. Acute arthritis of the hip--case series describing emergency physician performed ultrasound guided hip arthrocentesis. W V Med J. 2013 Sep-Oct; 109(5): 22-4.

[13] Atta D, Elsoaud AA, Hesham E, et al. Ultrasonography of the extremity. International Journal of Advanced Research. 2015; 3(10): 959-969.

[14] Trachtenberg F, Foote D, Martin M, Carson S, Coates T, Beams O, Vega O, Merelles-Pulcini M, Giardina PJ, Kleinert DA, Kwiatkowski J, Thompson AA, Neufeld EJ, Schilling L, Thayalasuthan V, Pakbaz Z, Yamashita R. Pain as an emergent issue in thalassemia. Am J Hematol. 2010; 85(5): 367-70.

[15] Noureldine MHA. Rheumatological complications of beta-thalassemia: an overview. Rheumatology. 2018; 57(1): 19-27.

[16] Choudhry VP, Pati HP, Saxena A, Malaviya AN. Deferiprone, efficacy and safety. Indian J Pediatr. 2004; 71: $213-6$. 
[17] Rheumatology Network. Identifying and managing hemochromatosis arthropathy. 2009.

[18] Mathiessen A, Conaghan PG. Synovitis in osteoarthritis: current understanding with therutapeutic implications. Arthritis Research \& Therapy. 2017; 19(8).

[19] Carotti M, et al. Power Doppler sonography in the assessment of synovial tissue of the knee joint in rheumatoid arthritis: a preliminary experience. Ann Rheum Dis. 2002; 61: 877-82.

[20] Jacobson JA. Knee Ultrasound. Fundamentals of Musculoskeletal Ultrasound. 2007; 238-239.

[21] Greenland S, et al. Statistical tests, $P$ values, confidence intervals, and power: a guide to misinterpretations. Eur J Epidemiol. 2016; 31: 337-50. 